\title{
5
}

\section{Electrochemical Preparation and Properties of Novel Conducting Polymers Derived from 5-Amino-2naphtalensulfonic Acid, Luminol and from Mixtures of Them}

\author{
Luz María Torres-Rodríguez, María Irene López-Cázares, \\ Antonio Montes-Rojas, Olivia Berenice Ramos-Guzmán \\ and Israel Luis Luna-Zavala \\ Laboratorio de Electroquimica/ Facultad de Ciencias Quimicas/ \\ Universidad Autónoma de San Luis Potosí, S. L. P
}

México

\section{Introduction}

Polyanilines contain anioniogenic functional groups are denominated self-doped polyanilines. These polymers possess properties different from those of polyaniline (PANI) as suppressed or no need on anion doping during oxidation or reduction processes, solubility in aqueous base, extended redox activity for neutral and basic solution, making them promising applications such as biosensors as a result of physiological $\mathrm{pH}$ values, and rechargeable batteries due to the fact that self doping polyanilines are capable of storing more specific energy than PANI as a function of self-doping (Malinauskas, 2004). Therefore it is important the development of these types of polymers, the electrochemical oxidation of 5-amino-2-naphtalensulfonic (ANS) and the luminol can be done a self-doped homopolymer, however the electropolymerizaton of these compounds has not been studied. The chemical structures of these monomers are similar in three aspects (Figure 1): (a) both ANS and luminol contain into their chemical structure the aniline; (b) It is difficult obtain a film of homopolymers to these monomers, because the electroxidation in milium acid of luminol produce a dimmer (De Robertis et al., 2008; Ferreira et al., 2008) in fact the solubility of luminol is bass in this milieu, in these conditions is favored the formation of dimmers; on the other hand no deposition of a polymer onto the electrode has been observed when others amino naphtalensulfonic acid has been electrochemically oxidate, probably for the reason that oligomers are very soluble (Mažeikienè \& Malinauskas, 2004). (c) A self-doped polymer can be obtained by copolymerization with aniline and whoever of these monomers (De Robertis et al., 2008; Ferreira et al., 2008, Mažeikienė \& Malinauskas, 2004).

So large of our knowledge there are no reports of the homopolymerization of ANS and luminol, the importance of the synthesis of each films consist in the case of ANS in obtain information of the effect of the separation of group sulfonic to aniline in the ion exchange of film, because the charge compensation has been evaluated principally for ring substituted 
anilines (Barbero et al., 1994; Cano-Márquez et al., 2007; Mello et al.,2000; Varela et al.; 2001). In the case of homopolymer of luminol should be studied as influence the chemical nature of film in the proprieties obtain and in the activity electrocatalitic; in fact these proprieties are only reported for the dimmer of luminol (Chen \& Lin, 2002). On other hand as the polymer obtained to luminol not is water soluble, in consequence the copolymerization of these two monomers can be result of a deposition a self doping polymer film. The goal of this study is the electrosynthes of three novel conducting polymers: polyANS, polyluminol (only has been reported dimmers of luminol) and copolymer, obtained to ANS, luminol and both respectivally, the evaluation of proprieties of films obtained as well as: activity electrocatalytic to ascorbic acid, electrochemical activity in $\mathrm{pH}$ neutral and study the charge compensation using the electrochemical quartz crystal microbalance (EQCM) during the redox process only for polyANS.<smiles>Nc1cccc2c(=O)[nH][nH]c(=O)c12</smiles>

Luminol (3-aminophtalhydrazide)

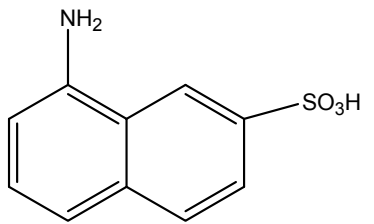

5-Amino-2-naphtalenesulfonic acid

Fig. 1. Chemical structure of momomers used in the present study.

\section{Experimental}

\subsection{Materials}

The commercial chemicals: luminol (Fluka), ANS (Aldrich), graphite powder (sigma), nujol (Alfa- Aesar), $\mathrm{HCl}$ (Fermont), $\mathrm{HClO}_{4}$ (Fermont), $\mathrm{HNO}_{3}$ (Caledón), $\mathrm{H}_{2} \mathrm{SO}_{4}$ (Fermont) and camphorsulfonic acid (Aldrich) were of analytical reagents grade and were used without further purification except the aniline (Sigma) which was distilled before use at stored to low temperature in the dark. The aqueous solutions were prepared using deionized water, and the solutions were deoxygenated by purging with nitrogen gas. After this, a nitrogen atmosphere was kept over the solution during each run.

\subsection{EQCM measurements}

EQCM measurements were conducted using a PAR 273A (Princeton Applied Research) potentiostat-galvanostat coupled to an electrochemical quartz crystal microbalance Seiko model QCA922, both controlled by WinEchem V. 1.5 installed in a personal computer. The quartz crystal resonator was mounted in a home-made acrylic cell (Figure 2). This cell is characterized by the commercial holder of quartz and it is united to made in home solution container, so the sample container also hold the quartz crystal. As the sample container is acrylic only aqueous solutions can be used with this cell. 

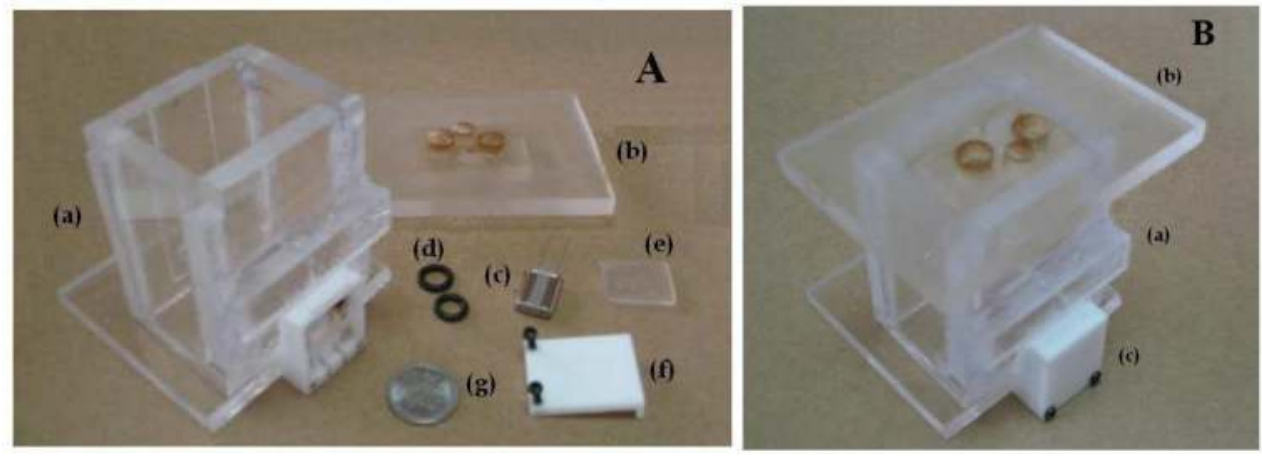

Fig. 2. Photograph of A) diassembled and B) assembled cell: (a) acrylic sample container, (b) acrylic cell cover, (c) teflon quartz crystal and his container, (d) O-rings, (e) acrylic cover of quartz cristal container, (f) teflon cover of quartz crista container and $(\mathrm{g})$ coin $(\phi=0.8 \mathrm{~cm})$.

\subsection{Electrochemical measurements}

Electrochemical experiments were carried out in a three-compartment cell in a high purity nitrogen atmosphere at room temperature. The electrode reference consisting of $\mathrm{Ag}|\mathrm{AgCl}| 3$ moldm ${ }^{-3} \mathrm{NaCl}$ (BAS) and the counter electrode was a platinum wire. The working electrodes were: carbon paste electrode $\left(0.1452 \mathrm{~cm}^{2}\right)$, glassy carbon, $\mathrm{Au}$ and $\mathrm{Pt}\left(0.0707 \mathrm{~cm}^{2}\right)$ and a $9 \mathrm{MHz}$ AT-cut quartz crystal coated with gold $\left(0.1963 \mathrm{~cm}^{2}\right)$. Two types of carbon paste electrode were prepared the first by intimately mixing $1.0 \mathrm{~g}$ of finely ground graphite powder with $1.0 \mathrm{~g}$ of Nujol. The second type of electrode is characterized by included the monomer into the carbon paste bulk, the electrode is prepared mixing graphite powder, nujol and the monomer. In both cases the resulting paste was then packed into a plastic 1 $\mathrm{mL}$ syringe in which a piece of coop wire was wound to produce the electrical contact. The surface was smoothed by a weight paper before each experience. The glassy carbon, Au and Pt electrodes were systematically polished successively with 3 and $1 \mu \mathrm{m}$ polish diamond (BAS) on a Microcloth felt disk (BAS). Following this, the electrodes were thoroughly rinsed with deionised water and sonicated in an ultrasonic bath for 10 minutes. The precoated PANI film for electrodeposition of polyANS was carried out by realizing 10 cycles of potential between -200 and $1200 \mathrm{mV}$, except for the three first cycles for which the upper limit was $1100 \mathrm{mV}$. The scan rate was $50 \mathrm{mVs}^{-1}$, and the electrolyte solution was $0.5 \mathrm{M} \mathrm{H}_{2} \mathrm{SO}_{4}$ $+0.5 \mathrm{M}$ aniline.

\section{Results and discussion}

\subsection{Electrosynthesis and characterization of polyANS}

The electrosynthesis of a film of polyANS was tested by chronopotenciometry and cyclic voltametry in five different electrodes: $\mathrm{Au}, \mathrm{Pt}$, glassy carbon, carbon paste and $\mathrm{Au}$ modified with PANI. No deposition of a polymer onto the Au, Pt and glassy carbon electrodes was observed, in agreement to reported for aminonaphtalen disulfonics acids (Mažeikienė \& Malinauskas, 2004) probably because the products formed during the oxidation are very solubles. On the contrary film growth was presented onto carbon paste and Au/PANI electrodes, the syntheses and properties obtained in each electrode are presented to continuation. 


\subsubsection{Electrosynthesis and electrogravimetric study of polyANS synthesized onto Au/PANI electrodes}

The syntheses electrochemical of film of PolyANS onto the Au/PANI electrode was carried out by cyclic voltametry, this modified electrode was used as working electrode for the reason that in earlier work it was demonstrated that contrary to the metallic electrodes a film of sulfonated PANI is obtained onto Au/PANI electrodes since, during electroxidation of PANI positive charges are generated at the polymer chain, which are compensated by incorporation of anions from the solution. Consequently, the $-\mathrm{SO}_{3}$ group of sulfonated PANI is incorporated to the PANI film as a dopant anion, anchoring sulfonated monomers on the PANI surface. Then, when the oxidation potential of monomers is attained the monomer is polymerized on PANI. During the reduction the anion cannot be ejected of PANI because the polymer synthetised is trapped within the PANI chains. (Cano-Márquez et al., 2007). Figure 3 shows curves obtained in diverse stages of growth of polyANS. At the very beginning of the electrodeposition the curve obtained is very similar to those of PANI (Shin-Jung \& Su-Moon, 2002), in fact, in this stage the polyANS produced is small in comparison to those of PANI as a result the response obtained is those of PANI, which is characterized by three well redox centered pair centered at around 250, 780 and $500 \mathrm{mV}$ corresponding to leucoemeraldine to emeraldine, emeraldine to pernigraniline redox transitions and sobreoxidation products respectively. When the cycle increase the response change gradually until become in those of polyANS, in fact the peaks attributed to oxidoreduction of film shift until overlapping (Figure 3). The reduced separation of the two peaks for sulfonated polyaniline has been associated with steric effects caused by the bulky sulfonic acid substituent (Wei et al., 1996; Yue et al., 1991). Additionally to the two oxidoreduction process of polyANS situated between 200 and $500 \mathrm{mV}$, the cyclic voltammogram of polyANS present a redox pair centered at around $540 \mathrm{mV}$, at present time no clear assignation can be proposed for this peak, however it can be speculated that have as origin the oxido-reduction of degradation products because is located of same potential of degradation products of PANI.

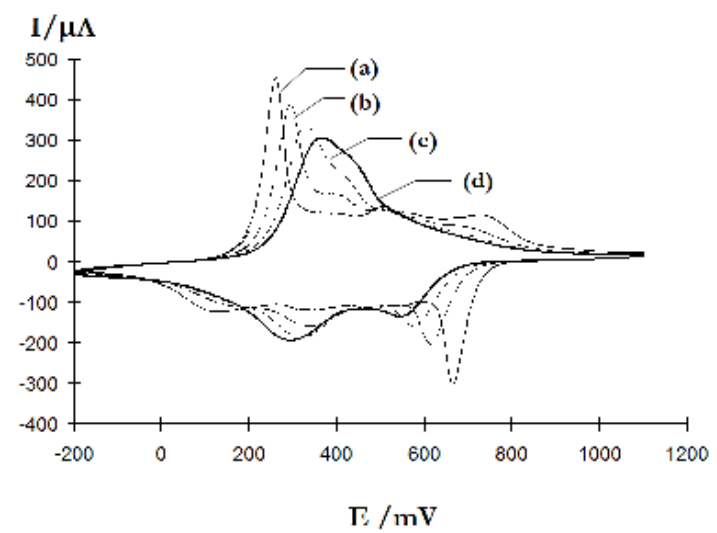

Fig. 3. Cyclic voltammograms of the 14th (a), 28th (b) 42th (c) and 56th (d) cycle of the electropolymerization of $1 \mathrm{mM}$ ANS in $0.5 \mathrm{M} \mathrm{H}_{2} \mathrm{SO}_{4}$, obtained onto $\mathrm{Au} / \mathrm{PANI}$ electrode. The potential was scanned from -200 to $1090 \mathrm{mV}$ at $100 \mathrm{mVs}^{-1}$. 
From the perspectives of electrochemical applications, arguably the most important underlying process of conducting polymers is the exchange between the films and ions molecules that accompany film redox switching. In case of sulfonated polyanilines is accepted that the charge compensation is accomplished mainly by the ejection of cations (Mello et al., 2000; Varela et al., 2000a, 2000b, 2001; Cano-Márquez et al.; 2007) in contrast with the behavior of PANI, which is carried out by the incorporation of anions (Hillman \& Mohamud, 2006). In order to define as is realized the charge compensation of polyANS electrochemical quartz crystal microbalance (EQCM) measurements were carried out in monomer free solution, the curves obtained were analyzed considering that the change of frequency is correlated to change of mass for the Sauerbrey equation (Donjuan-Medrano \& Montes-Rojas, 2008):

$$
\Delta f=-C_{\mathrm{f}} \Delta m=-\left(\frac{2 f_{0}^{2}}{\rho_{q} \vartheta_{q}}\right) \Delta m
$$

Where $\Delta \mathrm{f}$ and $\Delta \mathrm{m}$ are the change of frequency and the change of mass respectively, $\mathrm{C}_{\mathrm{f}}$ is the proportionality constant which depend of the base frequency $\left(f_{0}\right)$; density of quartz $\left(\rho_{q}\right)$ and the wave velocity within the quartz crystal $\left(v_{q}\right)$. The negative sign in the equation indicate that when the frequency increase the mass diminishes and when the frequency decreases the mass augment. In order to use the Sauerbrey equation it is necessary probe that the film deposited in the quartz is "rigid", it is the mass loading of the quartz crystal microbalance show ideal acoustic coupling to the crystal surface (Buttry \& Ward, 1992) and determinate experimentally the value of $C_{\mathrm{f}}$ (Donjuan-Medrano \& Montes-Rojas, 2008). In raison that in this work only a qualitative analysis was carried out, it was not required to validate the Souerbrey equation, neither it was indispensable determinate experimentally the value of $\mathrm{C}_{\mathrm{f}}$, only was assumed of Sauerbrey equation that:

$$
\Delta m=-C_{\mathrm{f}} \Delta
$$

It is that the change of mass is proportional to $-\Delta \mathrm{f}$. The obtained results for $\mathrm{H}_{2} \mathrm{SO}_{4}$ are shown in Figure 4 , in a first time the potentiodinamic profile of I and $-\Delta \mathrm{f}$ was analyzed over the range 200-900 $\mathrm{mV}$ (Figure 4a), it was observed that when the scan begin there are not redox process, so the frequency remain constant, to $300 \mathrm{mV}$ appear the oxidation peak this indicate that the polyANS is oxidate and positives charges in the polymer chain are generated, simultaneously a decrease of mass is presented, this mean that for maintain the electrical neutrality of the doped polyANS the charge compensation is carried out predominantly for ejection of cations from the polymer phase to the solution as is attaint for a self-doped polymer, when it was reach the potentials for the full oxidation of polymer an increase of mass was observed, contrary to decrease of mass observed for PANI in similar conditions (Orata \& Buttry, 1987). During the reverse sweep the mass decrease until finalized the reduction, it is the anion incorporated during the oxidation are ejected when the film back to netral condition, to end of scan the mass augment to until reach nearly the initial value. For the reason that the two peak of oxido-reduction of film are before $500 \mathrm{mV}$, the same experiment was repeated fixing the upper limit potential to $500 \mathrm{mV}$, as can be been in Figure $4 \mathrm{~b}$, the behavior is similar to those obtained for the extended range, in fact the mass of polyANS remains constant until the film commence the oxidation process in this moment the mass descend, this behavior indicate that the electroneutralization of film is achieved principally by expulsion of protons containing in the $-\mathrm{SO}_{3} \mathrm{H}$ group of polyANS, to higher potentials the mass increase, a similar behavior has 
been presented for sulfonated PANI (Varela et al., 2000). After the reverse of the scan direction the mass continue increase until the process of reduction begin, in this point the mass decrease, finally the mass increase attaint the value original. The experimental evidence presented above demonstrates that the charge process during the charge compensation is carried out principally by expulsion of cations of polyANS, however is not possible establish whether or not anion participation. In addition the evolution of frequency in the direct scan is completely different to those obtained in the inverted scan, it is the change of mass obtained is not reversible resulting in a broad frequency curve. This behavior is different to those obtained for sulfonated PANI (Mello et al, 2000; Varela et al. 2001) where the curves of frequency were more reversible. This behavior suggest that the electroneutralization is more complexes for the polyANS that for the films synthesized to anilines ring substituted by sulfonic groups, probably due the distance of the sulfonic group and nitrogen is much longer in polyANS that the anilines substituted directly in the ring for sulfonic groups, so in this case the electroneutralization is more easy.
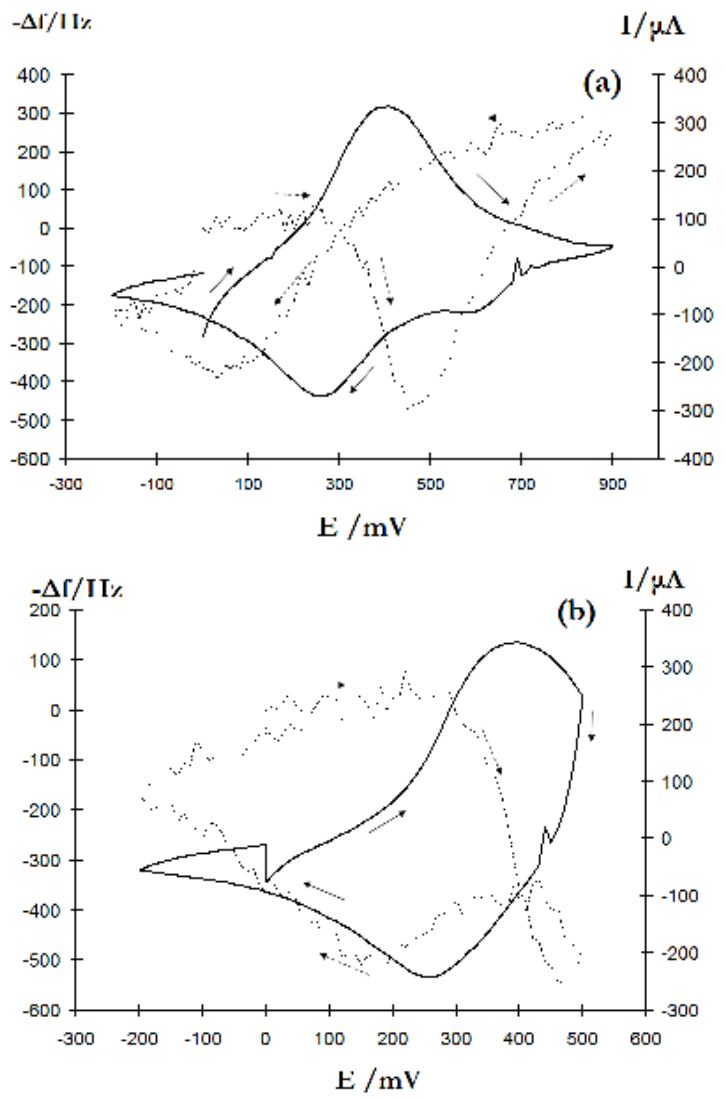

Fig. 4. Plot I/E (full line) and $-\Delta \mathrm{f} / \mathrm{E}$ (doted line) potentiodinamic profil for polyANS obtained for two upper limit (a) 900 and (b) $500 \mathrm{mV}$ in $\mathrm{H}_{2} \mathrm{SO}_{4} 0.5 \mathrm{M}$ electrolyte solution at $100 \mathrm{mVs}^{-1}$. 
In order to determinate whether there are or not anion participation in the electroneutralization of PolyANS, EQCM measurements were carried out in solutions for acids with anions of different molar mass: $\mathrm{H}_{2} \mathrm{SO}_{4}\left(96 \mathrm{gmol}^{-1}\right)$ (Figure 4), $\mathrm{HCl}\left(35.45 \mathrm{gmol}^{-1}\right)$, $\mathrm{HClO}_{4}\left(99.4 \mathrm{gmol}^{-1}\right), \mathrm{HNO}_{3}\left(62 \mathrm{gmol}^{-1}\right)$ and camphorsulfonic acid (HCS) which molar mass of anion is 231.1 gmol-1 $^{-1}$ (Figure 5). A decrease of mass is presented during the oxidation in $\mathrm{H}_{2} \mathrm{SO}_{4}, \mathrm{HCl}, \mathrm{HClO}_{4}$ and $\mathrm{HNO}_{3}$ showed that during the electroneutralization, protons are ejected to polyANS. However, a participation of anion can be proposed in reason of the marked dependence of frequency profile and cyclic voltammogram of anion of acids as is showed in Figure 4 and 5 . The decrease of mass $(-\Delta \mathrm{f})$ change with the acid used and not relation between the anion molar mass and the variation of frequency was present. These results show that the charge compensation of polyANS is carried out by both expulsion of protons and additions of anions, but the predominant process is the cation expulsion. In the HCS case also the electroneutralization is realized principally by proton expulsion despite the fact that the mass remain constant during the oxidation, in fact the change of mass registered are the sum of two contribution incorporation of anions and ejection of protons, as the frequency remains constant during the oxidation this mean that the augmentation of mass by incorporation of anions has the same value that the diminution of mass by expulsion of cations, this resultant is due to the molar mass of CS is more grand that those of the anions of other acids. Finally, it is important to note that the process of electroneutralization of polyANS is different of those of homopolymer of ortanilic acid, in
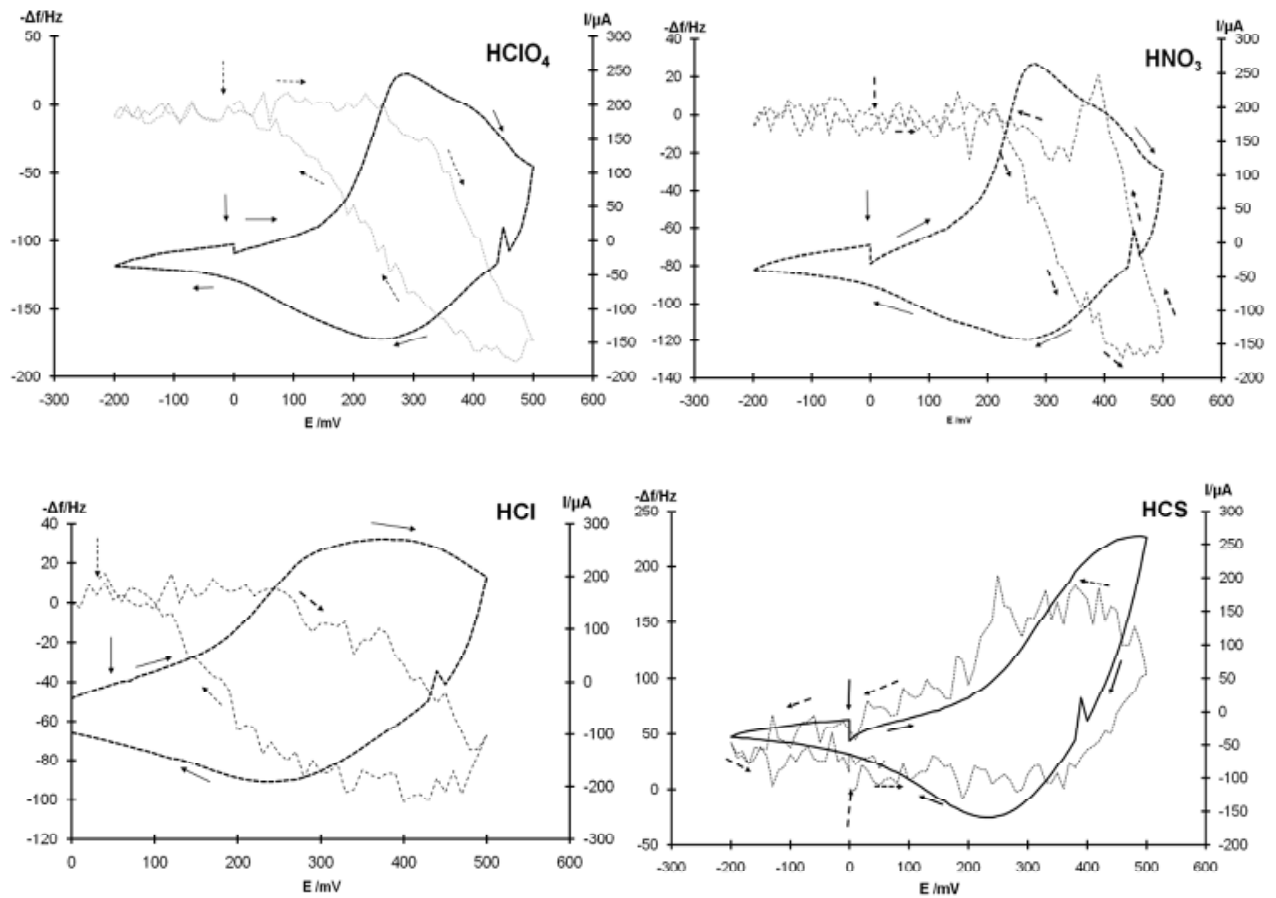

Fig. 5. Cyclic voltammograms and frequency responses recorded simultaneously of a polyANS film in dfferents $0.5 \mathrm{M}$ acids solutions. The scan rate was $100 \mathrm{mVs}^{-1}$. 
fact for this polymer the compensation of charge is carried out exclusively by ejection of protons and the profiles of change of frequency are very reversible (Cano-Márquez et al, 2007), which suggest that the process is more simple. The differences between these sulfonated homopolymers proved that the distance between the sulfonic group and the nitrogen impact in the electroneutralization process, when these groups are closer the cation participation is more important.

\subsubsection{Electrosyntheses of polyANS using carbon paste electrodes}

The electrodeposition of polyANS was also evaluated using carbon paste electrodes, the electrosynthesis was carried out by two methods with the monomer in solution and incorporated onto the carbon paste electrode. The results found employed the first methodology are presented in a subsequent section, in the case of the second mode the electrodeposition was realized potenciodinamic in a solution containing only $\mathrm{H}_{2} \mathrm{SO}_{4} 1 \mathrm{M}$ and the working electrode was carbon paste modified with ANS, the curve registered during the successive scans are presented in the Figure 6, this cyclic voltammogram is similar to those obtained with Au/PANI electrodes, in fact the curve can be show a shoulder and a broad peak situated around 309 and $424 \mathrm{mV}$ correspondingly, in the counterpart cathodic are two overlapping peak centered in 269 and $319 \mathrm{mV}$. Following an analogy to the parent polyaniline these peaks can be assigned to the leucoemeraldine to emeraldine transition and the emeraldine to perigraniline transition, respectively. Additionally a redox process appear around $100 \mathrm{mV}$, it not was possible the assignation of these peaks to an specific reaction, however it is possible that the peak correspond to the oxido-reduction of oligomers accumulate in the electrode, in fact these peaks not are observed when the response is analyzed in solutions basic. Subsequent cycles show anodic and cathodic current maxima with increasing currents, indicating progressive film formation. The electrochemical behavior of films synthetised was examined by cyclic voltametry, for this experience was necessary shift the upper limit potential to $600 \mathrm{mV}$, with the finality of avoid the oxidation of monomer and more film synthesis, it is examine only

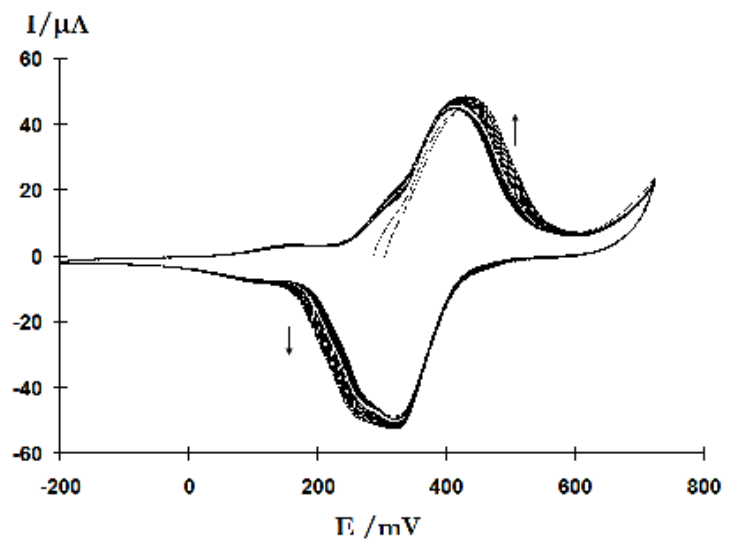

Fig. 6. Succesive cyclic voltammograms of a paste carbone electrode modified with ANS $\left(0.1452 \mathrm{~cm}^{2}\right)$ in $\mathrm{H}_{2} \mathrm{SO}_{4}(1 \mathrm{M})$. The composition of electrode was graphite powder, nujol and ANS in percentages of mass of $80,18.5$ and 1.5 respectively. Scan rate: $100 \mathrm{mVs}^{-1}$. 
the response of polyANS. The polymers which dissolve very slowly, it is when are cycled repeatedly diminish slightly the current intensity. The peak heights scale linearly with the sweep rate as is expected for a surface bound species.

The electropolymerization of ANS in carbon paste electrodes not modified with this monomer in solution were carried out by chronoamperometry and cyclic voltammeter. The results obtained with potentiodinamic methods are presented in the copolymer section, in the case of chronoamperometry the electroxidation was achieved with a solution formed only by ANS, since the monomer was used itself as an electrolyte, the potential was stepped in $1250 \mathrm{mV}$ during $60 \mathrm{~s}$. After the growth was terminated, the film was studied by recording cyclic voltamograms; the curves obtained are show in figure 7 . We note that the locations of the redox peak and the general appearance of the voltammogram are similar to sulfonated polyanilines o (Royappa et al., 2001; Nguyen et al., 1994) and the polyANS synthetised with $\mathrm{Au} / \mathrm{PANI}$ and carbon paste modified with ANS. The cyclic voltamogram obtained exhibit two broad and overlapping oxidation peak between 200 and $600 \mathrm{mV}$. The oxidation peak correspond to the oxidation of the neutral nitrogen atoms in the polymer backbone to form the radical carbon and dication ant they compare well with the peaks for PANI films (Buttry \& Ward, 1992). A process centered in 100, similar to those obtained with the monomer contain in the bulk paste electrode also appear when the electrodeposition is realized with the monomer in solution. A linear relationship was found between the peak current and scan rate, indicating that the elecroactive polymer film is well adhered to electrode. To investigate the influence of the $\mathrm{pH}$ on the redox behavior of the film, cyclic voltammograms of electrochemically synthesized films prepared under the same conditions as above, were recorded in solutions of different $\mathrm{pH}$ values. The voltammograms obtained are shown in Figure 7. One of the most obvious changes in the voltammetric behaviour of polymer in neutral and alkaline media in comparison to $\mathrm{pH}$ acid is the diminution in current, which is produced by the haut solubility of sulfonated polymer in $\mathrm{pH}$ neuter. In addition the peak attributed to polyANS shift not much to negative potentials. Thus the electroactivity of polyANS is practically independent of $\mathrm{pH}$ as is attaint for a self-doped polymer.

The same experiments were made with glassy carbon, $\mathrm{Au}$ and $\mathrm{Pt}$ as working electrode, the chronoamperograms obtained showed no rising transients, and no evidence of a film was obtained by cyclic voltammetry, in agreement with Mažeikienė et al, 2004. These results show that the polymerization of sulfonated monomers only can be carried out in carbon paste electrodes. The reasons for this positive deposition are unknown. However physic adsorption of monomers and oligomers in the paste carbone, it may be speculated

In this part of work was showed that the ANS can be polymerized in carbon paste and $\mathrm{Au} / \mathrm{PANI}$ electrodes, this result is contrary to those obtained for other amino naphtalensulfonic, in fact in this study is proved that is not possible the electrochemical homopolymerization of these type of compounds (Mažeikienè \& Malinauskas, 2004). Additionally is well established that Sulphonated anilines are difficult to polymerise under conventional conditions, in fact the haut solubility of film in aqueous milieu made difficult the synthesis of a film, the strategies employed for the electrodepositon of sulfonated homopolymer has been oriented to the diminution of solubility of oligomer, for this, the electropolymerization has carried out to bass temperatures and the combination of organic and aqueous solvents (Krishnamoorthy et al., 2002). In other works is reported the formation of sulfonated polymers using metallic electrodes however the polymerization rate is very bass (Zhang, L; 2006). The advantages of the use of Au/PANI and carbon paste 
electrodes for the electrosynthesis of sulfonated polymers in relation to other strategies is the facility to obtain thick films rapidly in working to room temperatures and with aqueous solutions.

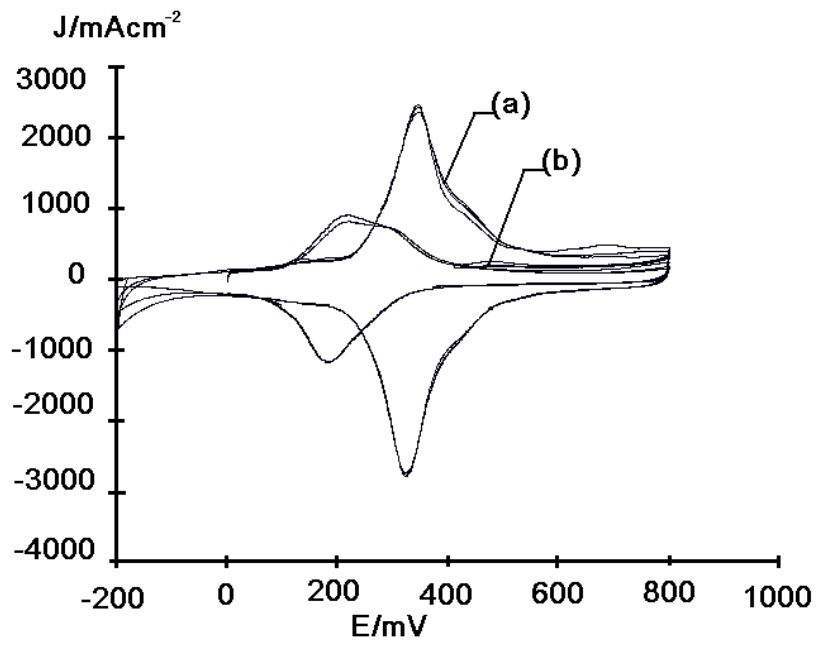

Fig. 7. Cyclic voltammograms of polyANS in: (a) $\mathrm{H}_{2} \mathrm{SO}_{4} 0.1 \mathrm{M}$ and (b) $\mathrm{Na}_{2} \mathrm{SO}_{4} 0.1 \mathrm{M}$. Synthesis of the films was performed by potential step at $1240 \mathrm{mV}$ using as working solution ANS $8 \mathrm{mM}$. Scan rate: $100 \mathrm{mV} / \mathrm{s}$.

\subsection{Electrodeposition and characterization of polyluminol}

\subsubsection{Electrosyntheses of polyluminol}

The films obtained of electrooxidation of luminol have been denominated polyluminol. However, different works have showed that the product obtained are dimmers and no polymers (Ferreira et al., 2008; Robertis et al., 2008), the chemical composition of film has been attributed to the bass solubility of monomer in solution. In order to obtain a polymer of luminol we propose increase the monomer concentration in the interface electrode/electrolyte using paste carbon electrodes bulk modified with luminol. The curves obtained during successive scan for two different upper limit potential $\left(\mathrm{E}_{\lambda}\right)$ are presented in figure 8 , in both cases the peaks due to the oxidation and reduction increase in intensity for each cycles as it is characteristic of growth of a film. The voltammogram acquired are different of those obtained with metallic electrodes in similar conditions, for the reason that additionally to process $B_{1} / B_{1}{ }^{\prime}$ presented in metallic electrodes (Chang et al., 2005; Kumar et al., 2009), a second process $B_{2} / B_{2}{ }^{\prime}$ is presented. A similar process to $B_{2} / B_{2}{ }^{\prime}$ is obtained for the copolymers of aniline and luminol synthesised using solutions with more concentration of luminol that aniline (Roberti et al., 2008; Ferreira et al., 2008) and during the oxidation of luminiol in higher potentials $1.2 \mathrm{~V}$ (Zhang \& Chen, 2000). Additionally the aspect of voltammogram presented in Figure 8 is very similar to those of copolymer therefore probably this peak are associated to polymer formation. The current of process $B_{2} / B_{2}{ }^{\prime}$ by rapport to $B_{1} / B_{1}{ }^{\prime}$ is strongly dependent of upper limit potential, for $E_{\lambda}=0.9 \mathrm{~V}$ the intensity of current $B_{2} / B_{2}{ }^{\prime}$ is very small in comparaison with those $B_{1} / B_{1}{ }^{\prime}$, while that when $E_{\lambda}=0.8$ the 
current of $B_{1} / B_{1}{ }^{\prime}$ is only environ three fold more grand that $B_{2} / B_{2}{ }^{\prime}$. This dependence show that product correspondent to peaks $B_{1} / B_{1}{ }^{\prime}$ are produced in more quantity when $E_{\lambda}$ is more higher. Two difference important were observed in voltammogramas obtain using two differents $E_{\lambda}$, first, the evolution of the intensity of current, For $E_{\lambda}=0.9 \mathrm{~V}$ the current of peaks $B_{1}$ and $B_{1}{ }^{\prime}$ increase significantly the first cycles, after remain almost constant, while that for $\mathrm{E}_{\lambda}=0.8 \mathrm{~V}$, the current augment slowly but continually, this last evolution of current is more congruent with a polymerization. The second is relationated with the peak $B_{1} / B_{1}{ }^{\prime}$, for $\mathrm{E}_{\lambda}=0.8 \mathrm{~V}$, the peak is more broader that for $\mathrm{E}_{\lambda}=0.9 \mathrm{~V}$ in addition in some cycles is possible to observe that the peak is the resultant of the overlap of two peaks, probably those of the dimmer or degradation oxidation and those of the bipolaron state of polymer. It is we propose that the peak $\mathrm{B}_{1} / \mathrm{B}_{1}{ }^{\prime}$ and $\mathrm{B}_{2} / \mathrm{B}_{2}{ }^{\prime}$ can be assigned to polaron and bipolaron states of polymer respectively; because the voltammograms are very similar to those of copolymer formed by aniline and luminol and those of sulfonated polyanilines.

Finally the film were analysed in $\mathrm{H}_{2} \mathrm{SO}_{4}$ solution by cyclic voltammetry, for this $\mathrm{E}_{\lambda}$ was shifted to more negatives potentials in order to avoid the oxidation of monomer in the bulk electrode paste. Voltamograms were carried out for different scan rates, the peak heights scale linearly with the sweep rate and the cathodic and anodic peak separation remains constant as it is attaint for an electroactive specie fix to surface electrode.

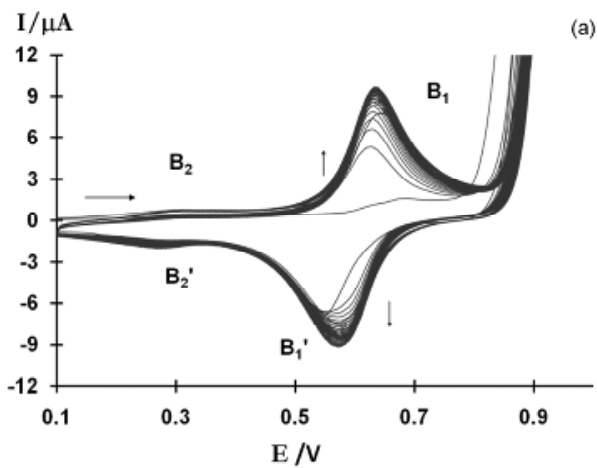

(a) $I / \mu \mathrm{A}$

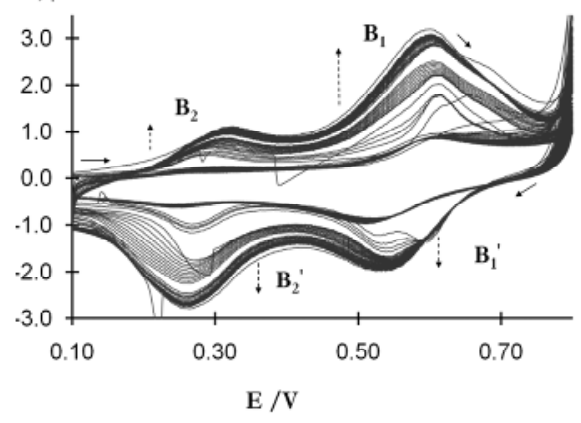

(b)

Fig. 8. Subsequent multisweep cyclic voltammograms obtained in a $\mathrm{H}_{2} \mathrm{SO}_{4}(0.5 \mathrm{M})$, the upper limit were: (a) 0.9 and (b) $0.8 \mathrm{~V}$. The working electrode was paste carbon electrodes formed by: graphite $(60 \%)$, nujol $(26 \%)$ and luminol $(14 \%)$. The scan rate was $100 \mathrm{mVs}^{-1}$.

In order to determinate weather the monomer concentration affect the electrosyntheses of film of polyluminol, electrodeposition were carried out employing carbon paste electrodes modified with different percentages of luminol, the results are presented in Figure 9, the voltamogramms have the same aspect, only they are differenced by the intensity in current which increase with the quantity of monomer in the bulk carbon paste electrode. This means that only the quantity of film is affected by the quantity of momomer. A similar experiment was achieved using a carbon paste electrode not modified and a solution with luminol, the curve obtained has an aspect equal to those obtained with modified electrode. It can be speculated that the curve not change with luminol concentration in the interface electrode/electrolyte, since when the monomer is in solution, the luminol is adsorbed in the electrode surface and the concentration in the interface is increase by preconcentration, so the concentration of luminol is more elevated than the metallic electrodes. 

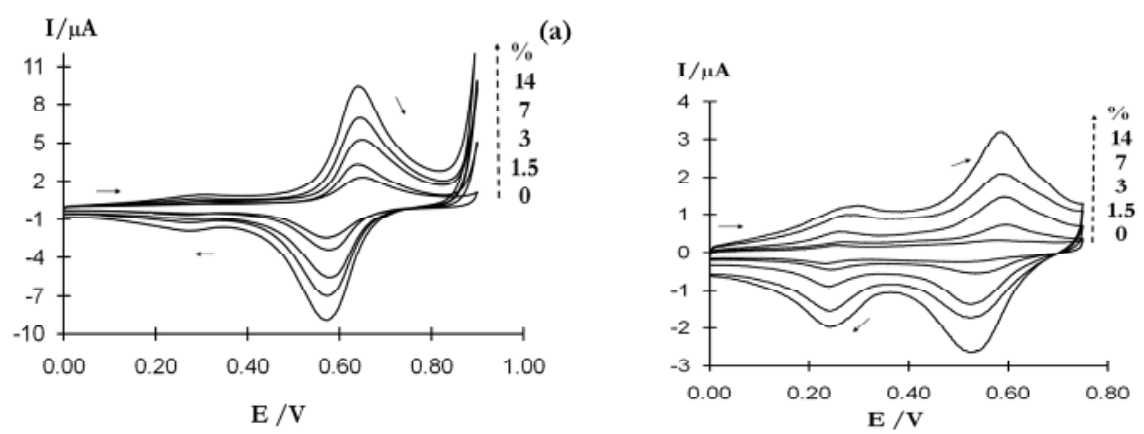

(b)

Fig. 9. Cyclic voltammograms $\left(50 \mathrm{mVs}^{-1}\right)$ of electrochemically synthesised polyluminol in 0.5 $\mathrm{M}$ aqueous $\mathrm{H}_{2} \mathrm{SO}_{4}$. The films were synthetised with the conditions of Figure 8 with

(a) $\mathrm{E}_{\lambda}=0.9$ and (b) $\mathrm{E}_{\lambda}=0.8 \mathrm{~V}$. The composition of carbon paste was graphite $(60 \%)$, luminol (indicated in the Figure) and nujol (the necessary to reach the 100\%). El $0 \%$ indicate the film synthesised with the luminol in solution $(1 \mathrm{mM})$.

\subsubsection{Electrochemical activity of polyluminol to $\mathrm{pH}$ neutral}

It is proved that the films obtained to oxidation of luminol are self-doped (Ferreira et al., 2008), this implicate that they are electroactive to $4<\mathrm{pH}$. Figure 10 shows the voltammograms for polyluminol synthesised with $\mathrm{E}_{\lambda}=0.8 \mathrm{~V}$ at acid and neutral $\mathrm{pH}$. It can be observed that the peaks shift slightly to lower potentials in a $\mathrm{Na}_{2} \mathrm{SO}_{4}$ aqueous solution (1 $\mathrm{M})$, when the same experiment is carried out with posphate buffers solution, $\mathrm{pH}=7$, (PBS) the peaks of polyluminol overlap into only one, while the current of this process remain in similar values. The difference between the voltamperometric responses at two electrolytes of a similar $\mathrm{pH}$, probably is due to the charge/discharge process because the anion and cations are different. This behaviour in neutral milieu is similar to those observed in sulfonated polyanilines (Sanchís et at., 2008; Kariakin et al., 1994), and as a consequence congruent with the behaviour of a polymer. It is important note that an irreversible oxidation is observed in buffer solution (inset Figure 10), correspondent to the oxidation of monomer in the bulk electrode.

To compare the properties of polyluminol synthesized to monomer in solution and in the bulk carbon paste, cyclic voltammogramms in supporting electrolyte solutions acid and neutral $\mathrm{pH}$ were investigated. Figure 11 shows voltammograms for polyluminol films obtained in acid and neutral electrolytes. The films are quite electrochemicaly active in both neutral solutions $\mathrm{Na}_{2} \mathrm{SO}_{4}$ and PBS, in $\mathrm{Na}_{2} \mathrm{SO}_{4}$ a shift to more positives potentials was observed and in PBS an overlap of the two peak was presented. However we note that the more defined and reversible peak in the case of films synthesised with the monomer in the bulk paste carbon electrode, in addition the relation between the anodic current peak in acid solution $\left(\mathrm{I}_{0}\right)$ respect to those obtained in milieu neuter PBS (IPBS) or $\mathrm{Na}_{2} \mathrm{SO}_{4}\left(\mathrm{I}_{\mathrm{S}}\right)$, were $\mathrm{I}_{\mathrm{PBS}} / \mathrm{I}_{0}$ $=0.579$ and $\mathrm{I}_{\mathrm{PBS}} / \mathrm{I}_{0}=1.249$, while that when the films were made to monomer in solution $\mathrm{IPBS}_{\mathrm{PB}} / \mathrm{I}_{0}=0.487$ and $\mathrm{IPBS}_{\mathrm{P}} \mathrm{I}_{0}=0.412$. A comparable tendance was showed for films obtained with other percentages of luminol in carbon paste 1.5, 3 and $7 \%$. These result demonstrate that in terms of extension of its electrochemical properties to high $\mathrm{pH}$, are better the films elaborated to modified carbon paste electrodes than those carried out the monomer in solution. 


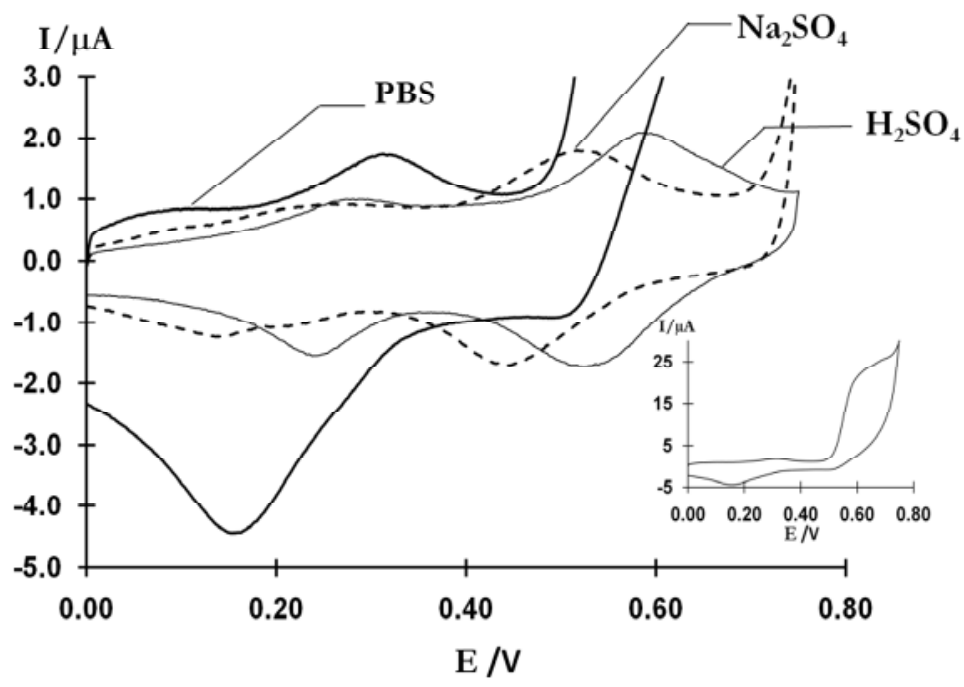

Fig. 10. Cyclic voltammograms for polyluminol synthesised using $\mathrm{E}_{\lambda}=0.8 \mathrm{~V}$ and carbon paste electrode graphite $(60 \%)$, luminol (7\%) and nujol (33 \%) at differents electrolytes. Scan rate $=100 \mathrm{mVs}^{-1}$. Inset complete cyclic voltammogram for polyluminol at PBS.
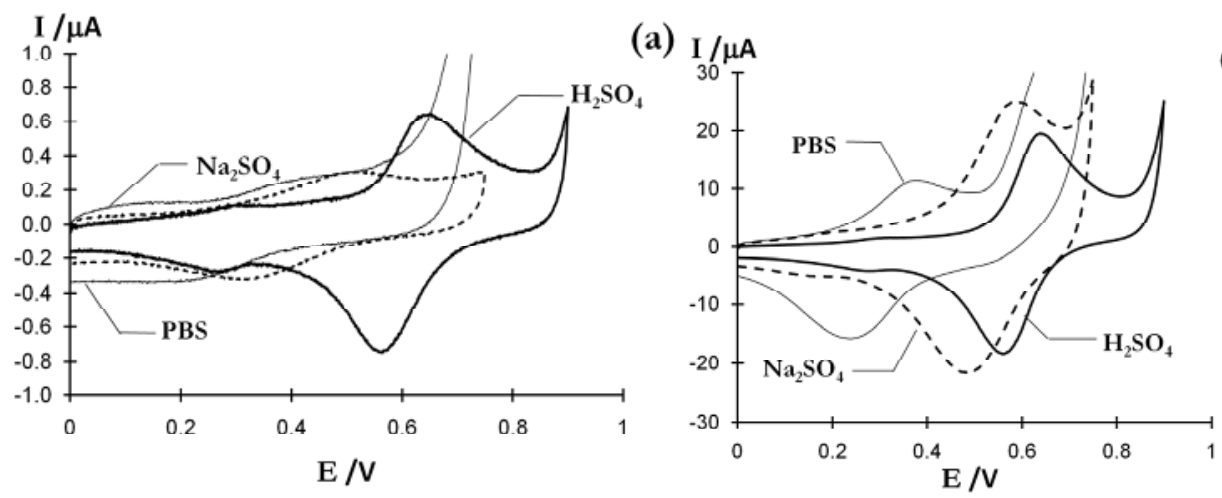

(b)

Fig. 11. Cyclic voltammetry of polyluminol, obtained in different supporting electrolytes containing: $\mathrm{H}_{2} \mathrm{SO}_{4}(0.5 \mathrm{M}), \mathrm{Na}_{2} \mathrm{SO}_{4}(1 \mathrm{M})$ and phosphate buffer solution $(\mathrm{pH}=7)$. Synthesis of the films was performed as indicate in Figure 8a, using: (a) luminol $(1 \mathrm{Mm})$ in $\mathrm{H}_{2} \mathrm{SO}_{4}(0.5$ $\mathrm{M})$ and (b) a modified carbon paste electrode (14\%).

\subsubsection{Electrochemical oxidation of ascorbic acid}

A more extended applications of polyluminol films and its derivatives is the electrocatalysis of ascorbic acid (Chen \& Lin, 2002; Ashok et al., 2009; Ma et al., 2010; Kumar et al., 2009a; Kumar et al., 2009b). As the potentiodinamic response of films obtained using carbon paste electrodes are different to those synthesised with metallic electrodes; in fact the cyclic voltammogram is more similar to those of copolymers of aniline and luminol, we think that 
the chemical composition of films in carbon paste correspond to those of a polymer, this supposition is supported by the behaviour of films in neutral solutions. In order to determinate weather the chemical composition of deposits of luminol affect or not the catalytic properties of films, the electoxidation of ascorbic acid (aa) was studied with the films obtained and compared with those of metallic electrodes, the curves obtained are presented in Figure 12, as can be seen, the oxidation peak current augment with increasing aa concentration. The inset of Figure 12 shows that the anode peak current is linearly dependent on the aa concentration in the studied range, to slope of line was obtaining the sensibility that was $43.2 \mu \mathrm{AmM}^{-1}$, this value is the double of those obtained using a polyluminol synthetised in a metallic electrode. This result show that the electrocatalytic activite of polyluminol film is enhanced with is obtained in carbon paste electrodes.

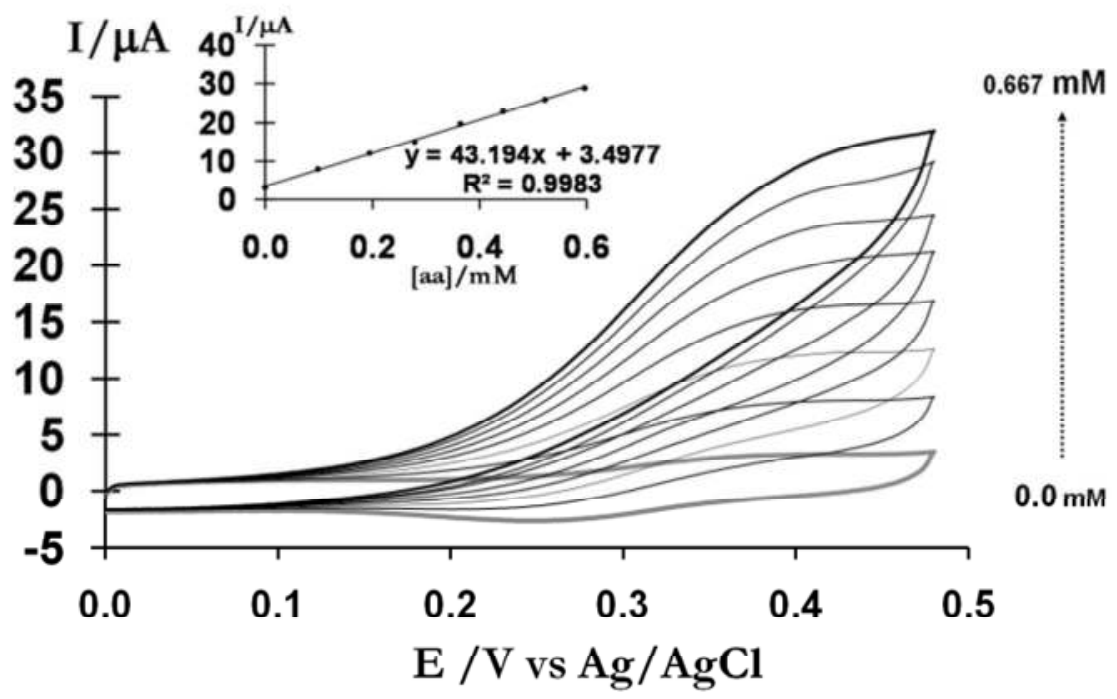

Fig. 12. Cyclic voltammetry of polyluminol in PBS containing different concentrations of aa: $0,0.098,0.195,0.279,0.364,0.444,0.522,0.596$ and $0.667 \mathrm{mM}$. The film was synthesised like those of Figure $8 \mathrm{~b}$. The scan rate was $100 \mathrm{mVs}^{-1}$.

\subsection{Electrodeposition of copolymer}

Finally we have tried the electrosynthesis of a novel self-doped polymer formed by ANS and luminol, in fact the electroxidation of both compound can to produce self-doping polymers, However the polyANS is soluble in milieu neuter, this characteristic limit its use in biosensors, while the polyluminol is insoluble but the electrochemical activity is more dependent of $\mathrm{pH}$ in comparison with the polyANS in reason of the $-\mathrm{SO}_{3} \mathrm{H}$ is a strong acid. The combination of both monomers can be produced an insoluble polymer which present electrochemical activity in a wide $\mathrm{pH}$ range.

\subsubsection{Electrochemical properties of monomers}

In order to determinate the potential which both monomers are oxided, potenciodynamic experiments were carried out (Figure 13a), the voltammograms exhibit a broad irreversible 
anodic peak situated in the $0.7-1.2$ Vand 0.9 and $1.2 \mathrm{~V}$ for ANS and luminol respectively. The anodic response correspond to the irreversible oxidation of monomers entities, the potential where the oxidation of both monomers is carried out is environ $0.9 \mathrm{~V}$. The effect of the scan rate in the intensity of current was studied, in the Figure $13 \mathrm{~b}$ can be observed that in the case of ANS the peak heights are linear with the square root of sweep rate in all range studied, this mean that the oxidation of ANS is controlled by diffusion; while in the luminol case the peak heights scale linearly with the square root of sweep rate only in the range between 5 and $100 \mathrm{mVs}^{-1}$, in consequence for higher sweep rate, the process of oxidation can be controlled by adsorption or a combination of adsorption and diffusion. It is important note that the slopes of both curves are essentially identical, in considering the RandlesSevcik can be established that the Diffusion coefficient of both monomers should be very similar. The oxidation of both monomers is $0.9 \mathrm{~V}$ and in order to both monomes are in the same regime of mass transfer it is convenient working to sweep rate $\leq 100 \mathrm{mVs}^{-1}$.

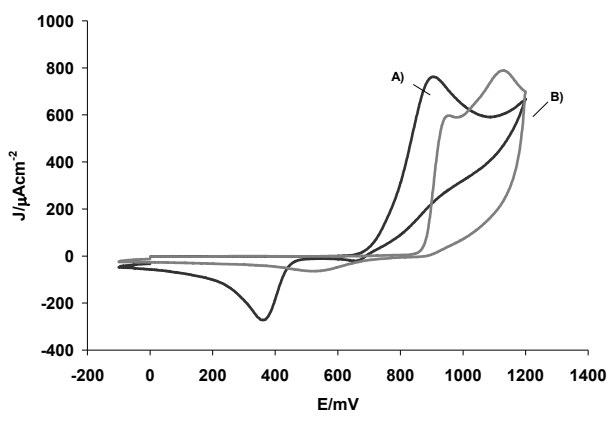

(a)

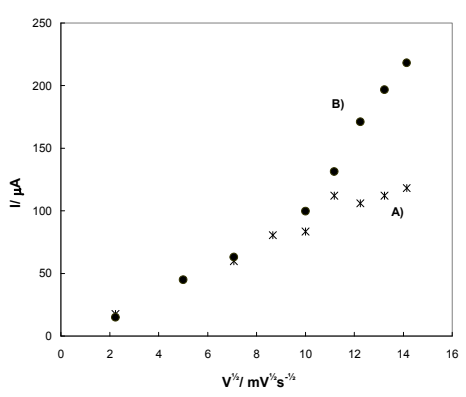

(b)

Fig. 13. (a) Cyclic voltammetric response of: (A) ANS (0.8 mM) and (B) luminol (0.8 $\mathrm{mM})$ on a carbon paste electrode $\left(0.1452 \mathrm{~cm}^{2}\right)$ in $\mathrm{H}_{2} \mathrm{SO}_{4} 1 \mathrm{M}$. The carbon paste was formed by a mixture 1:1 of luminol and graphite. Potential scan rate $100 \mathrm{mVs}^{-1}$. (b) Dependence of anodic peak current with the square root of sweep rate

\subsubsection{Electrochemical synthesis and characterization of copolymers}

The copolymers were synthesised using a $\mathrm{H}_{2} \mathrm{SO}_{4}(1 \mathrm{M})$ solution contain luminol $(0.8 \mathrm{mM})$ and ANS $(0.8 \mathrm{mM})$ as working electrode carbon paste electrode was used, 50 potential cycles were carried out between 0 y $0.9 \mathrm{~V}$. Concurrently the same experiment was repeated with a solution contain only a monomer. After their electrosyntesis, copolymers and homopolymers were characterised by cyclic voltametry in $1 \mathrm{M} \mathrm{H}_{2} \mathrm{SO}_{4}$ (Figure 14), in orden to avoid the sobreoxidation of films the upper potentials were shifted to lower values. The cyclic voltammogram of copolymer was characterised by present two redox process, attributed in analogy with polyluminol and polyANS to partial and total oxidation of polymer. Comparison of the peak of copolymer with those of luminol and ANS taken under similar conditions indicate that the potential and the current of copolymers peak lies between them. This suggest that the films prepared by this procedure are indeed copolymers and not just mixtures of polyluminol and polyANS. We have tried to modulate the amount of lumiol in the copolymer film. To do this, the electrosynthesis of copolymers 
was performed using different ratios of luminol and ANS, in addition the potential scan rate was changed. Concerning the ratio of monomer when the amount of luminol increase in solution the cyclic voltammogram of copolymer present current and potentials mores similar to those of luminol, while that when it is augmented the amount of ANS in comparison to those of luminol in solution, the potentiodynamic response of copolymer is more near to those of polyANS. Thus, it is possible modulate the monomer proportion in the film changing the ratio of monomer in the electrosynthesis solution.

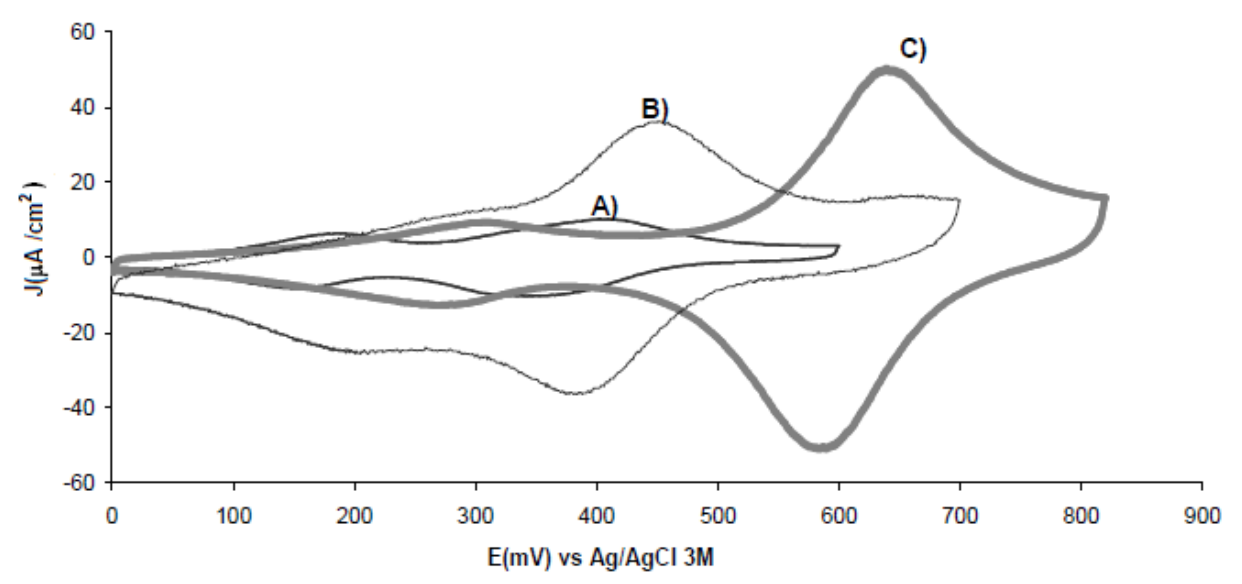

Fig. 14. Voltammograms for (A) polyANS, (B) copolymer and (C) polyluminol films obtained in $\mathrm{H}_{2} \mathrm{SO}_{4}(1 \mathrm{M})$. Potential scan rate $100 \mathrm{mVs}^{-1}$.

On the other hand, as can be been in Figure 14 and Figure 15 the potentiodynamic response is dependent of the scan rate used during the electropolymerization, in the case of homopolymers the current change with this parameter in contrast the potential is the same for all scan rate studied. This indicate that only change the amount of film obtained and the chemical composition is the same, in the copolymer case both current and potential are dependent of potential scan rate Therefore the amount and composition of films synthesized are modified with the scan rate. These facts could be related with the solubility of films, because the products of oxidation of ANS are more soluble that those of luminol, since to lower scan rate the oligomers formed have time for a probable adsorption in the surface of paste carbon, since the polymerization of ANS is enhanced to low scan rate (Figure 15a). The products of luminol are insoluble and are less dependent to the scan rate, since the proportion of luminol and ANS onto the film are dependent of this variable.

The electroactivity of copolymers was analysed in neutral solutions by cyclic voltammetry, as can be showed in Figure 16, the curves obtained show process redox, this indicate that are electrochemical activity to $\mathrm{pH}$ neutral. This result is congruent with the behaviour of a self-doped polyaniline. The response was affected by the ratio of monomers in the films, for the films obtained to $5 \mathrm{mVs}^{-1}$ the behaviour was similar to those of polyANS, while the film synthetised to $100 \mathrm{mVs}^{-1}$ the cyclic voltammogram was similar to those of polyluminol. 

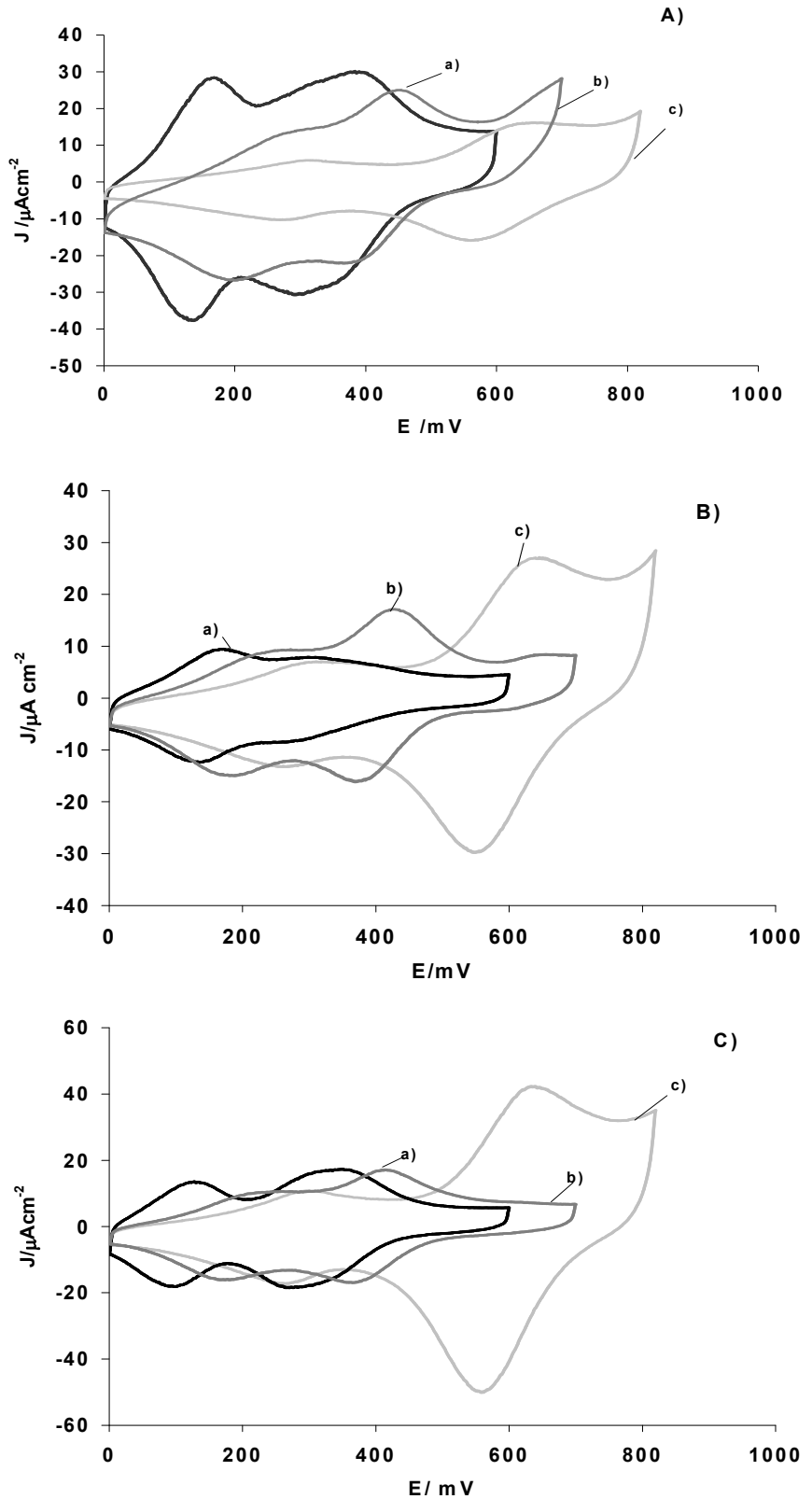

Fig. 15. Voltammograms for (a) polyANS, (b) copolymer and (c) polyluminol films obtained in $\mathrm{H}_{2} \mathrm{SO}_{4}(1 \mathrm{M})$. Potential scan rate $100 \mathrm{mVs}^{-1}$. The scan rates used during the electrodeposition were: (A) 5, (B) 25 and (c) $50 \mathrm{mVs}^{-1}$. 

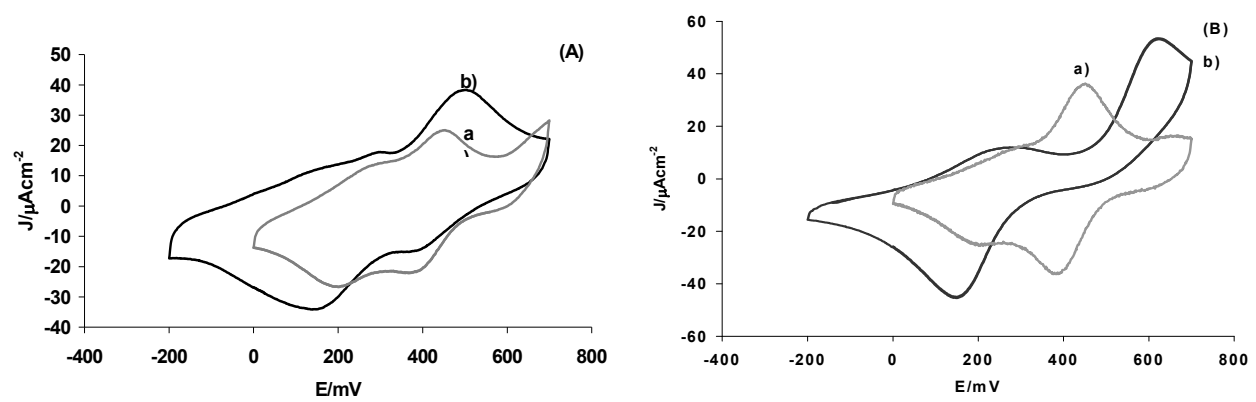

Fig. 16. Cyclic voltammograms of copolymer synthesised to (A) 5 and (B) $100 \mathrm{mVs}^{-1}$ in (a) $\mathrm{H}_{2} \mathrm{SO}_{4}(1 \mathrm{M})$ and $\mathrm{Na}_{2} \mathrm{SO}_{4}(1 \mathrm{M})$. The scan rate was $100 \mathrm{mVs}^{-1}$.
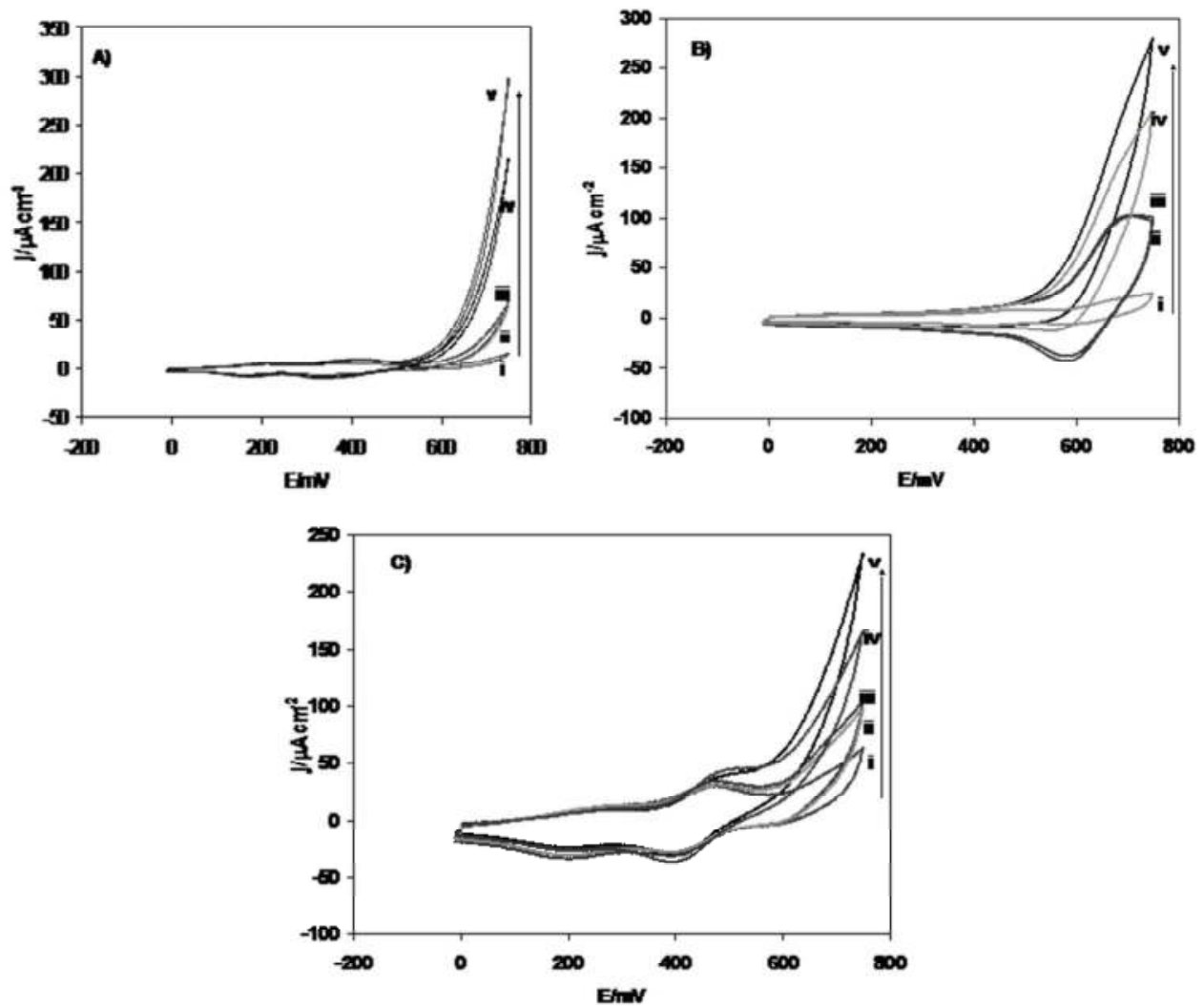

Fig. 17. Cyclic voltammograms curves for (A) polyANS, (B) polyluminol and (C) copolymer electrode in the prescence of (i) 0.1 , (ii) 0.2 , (iii) 0.4 , (iv) 0.6 and (v) $0.8 \mathrm{mM}$. Supporting electrolyte $\mathrm{H}_{2} \mathrm{SO}_{4} 1 \mathrm{M}$. The scan rate was $100 \mathrm{mVs}^{-1}$. 


\subsubsection{Electrocatalytic oxidation of ascorbic acid}

Finally the oxidation of aa was analysed in the copolymer and comparated with those of homopolymers, Figure 17 show the ascorbic acid oxidation on the different films, immersed in $1 \mathrm{M} \mathrm{H}_{2} \mathrm{SO}_{4}$ solution in the absence and in the presence of different concentrations of ascorbic acid. An increase in intensity of the anodic current peak, as the acid ascorbic concentration was increased is an indication of catalytic oxidation of ascorbic acid mediated for each film. The effect catalytic of polyluminol in the oxidation of aa is well established (Chen \& Lin, 2002), however the electrocatalysis in polyANS and copolymer has been not reported. The current obtained for a same concentration of aa is higher in the polyANS this suggest that the catalysis is more favourable for this film.

\section{Conclusion}

In conclusion we have found that it is posibble the formation of polymer of ANS, when the electroxidation of monomer is carried out in PANI/Au or carbon paste electrodes. The films obtained are electrochemically active in neutral $\mathrm{pH}$. The charge compensation of this film is carried out principally by ejection of cation, but anion insertion is simultaneuslly presented. On other hand, the electrochemical polymerization of luminol in carbon paste electrodes give a film with characteristic of a seld-doped polymer contraty to the film obtained using metallic electrodes which are dimmers. A polymer was synthetised to luminol and ANS, the cyclic voltammogram obtain show peak intermediate beetween luminol and ANS, the film can catalize the oxidation of aa and is electroachemically active to neutral $\mathrm{pH}$, the proportion of monomers in the film can be modulate by the solution composition and the scan rate.

\section{Acknowledgment}

This work was supported by the SEP (C06-PIFI-03.18.18) and CONACYT (C01-AINAT-0139.39).

\section{References}

Barbero, C. \& Kötz, R. (1994). Electrochemical formation of a selfdoped conductive polymer in the absence of an supporting electrolyte. The copolymerization of 0 aminobenzensulfonic acid and aniline, Advanced Materials, Vol. 6, No. 7-8; (JulyAugust 1994), pp. 577-580, ISSN 1521-4095

Buttry, D.A. \& Ward, M.D. (1992). Measurement of interfacial processes at electrode surfaces with the electrochemical quartz crystal microbalance. Chemical Review Vol. 92, No. 6, (September 1992), pp. 1355-1379, ISSN 0365-6675

Cano-Márquez, A.G.; Torres-Rodríguez, L.M. \& Montes-Rojas, A. (2007). Synthesis of fully and partially sulfonated polyanilines derived of ortanilic acid: an electrochemical and electromicrogravimetric study, Electrochimica Acta, Vol. 52, No. 16, (April 2007), pp. 5294-5303, ISSN 0013-4686 
Chang, Y.T. ; Lin K.C. \& Chen, S.M. (2005). Preparation characterization and electrocatalytic properties of poly(luminol) and polyoxometalate hybride film modified electrodes, Electrochimica Acta, Vol. 51, No. 3; (October, 2005) pp. 450-461. ISSN 0013-4686.

Chen, S. M. \& Lin, K.C. (2002). The electrocatalytic properties of biological molecules using polymerized luminol film-modified electrodes, Journal of Electroanalytical Chemistry, Vol. 523, No. 1-2, (April 2002), pp. 93-105, ISSN 0022-0728

De Robertis, E.; Neves, R.S. \& Motheo, A.J. (2008). Electropolymerization Studies of Pani/polyluminol over platinum electrodes, Molecular Crystals and Liquid Cristals, Vol. 484, pp. 322-334, ISSN 1542-1406

Donjuan-Medrano, A.L. \& Montes-Rojas, A. (2008). Effect of the thickness of thallium deposits on the values of EQCM sensitivity constant, New Journal of Chemistry, Vol. 32, No. 11, pp. 1935-1944, ISSN 1144-0546

Ferreira, D. ; Cascalheira, A.C. \& Abrantes, L.M. (2008). Electrochemical copolymerisation of luminol with aniline: A new route for the preparation of self-doped polyanilines, Electrochimica Acta, Vol. 53, No. 11, (April 2008), pp.3803-3811 ; ISSN 0013-4686

Hillman, A.R \& Mohamoud, M.A. (2006). Ion, solvent and polymer dynamics in polyaniline conducting polymers films, Electrochimica Acta, Vol. 51, No. 27; (August 2007) pp. 6018-6024. ISSN 0013-4686

Karyakin, A.A. ; Strakhova, A.K. \& Yatsimirsky, A.K. (1994). Self-doped polyanilines electrochemically active in neutral and basic aqueous solutions. Electropolymerization of substituted anilines. Journal of Electroanalytical Chemistry, Vol. 371, No. 1-2, (June, 1994), pp. 259-265. ISSN 0022-0728

Krishnamoorthy, K ; Contractor, A.Q \& Kumar, A. (2002). Electrochemical Synthesis of fully sulfonated polyanilines n-dopable polyaniline: poly(metanillic acid), Chemical Communications, No. 3, (December 2001), pp. 240-241, ISSN 1359-7345

Kumar, A.S ; Chen, H.W \& Chen, S.M. (2009a). Electroanalysis of ascorbic acid (vitamine C using nano-ZnO/poly(luminol) hybrid film modified electrode, Reactive $\mathcal{E}$ Functional Polymers, Vol. 69, No. 6, (June 2009), pp. 364-370, ISSN 1381-5148.

Kumar, A.S. ; Chen, H.W ; Chen, S.M. (2009b). Selective detection of uric acid in the presence of ascorbic acid using polymerized luminol film modified glassy carbon electrode, Electroanalysis, Vol. 21, No. 2, (Octobre, 2009), pp. 2281-2286, ISSN 10400397

Ma, J. ; Wang, S.R.; Wang, M.Q.; Zhang, J.L.; Wang, L.A. \& Du, X.Y. (2010). Polyluminol/Single walled carbon nanotubes composites film-modified electrodes for simultaneous determination of propyl gallate and ascorbic acid, Sensor letters, Vol. 8, No. 4; (August 2010) pp. 672-676. ISSN 1546-198X

Malinauskas, A. (2004). Self-doped polyanilines, Journal of Power Sources, Vol. 126, No. 1-2, (February 2004), pp. 214-220, ISSN 0378-7753

Mažeikienè, R. \& Malinauskas, A. (2004). Electrochemical preparation and study of novel self-doped polyanilines, Materials Chemistry and Physics, Vol. 83 ; No. 1 ; (January, 2004), pp. 184-192 ; ISSN 0254-0584.

Mello, R.M.Q ; Torresi, R.M. ; Córdoba de Torresi, S.I. ; Ticianelli ; E.A. (2000). Ellipsometric, electrogravimetric and spectroelectrochemical studies of the redox process of 
sulfonated polyaniline, Langmuir, Vol. 16, No. 20, (June, 2000), pp. 7835-7841, ISSN 0743-7463.

Nguyen, M.T. ; Kasai, P. ; Miller, J.L. ; Díaz, A. F. (1994). Synthesis and Properties of Novel Water-Soluble Conducting Polyanilines copolymers, Macromolecules, Vol. 27, No. 3 , (June 1994), pp. 3625-3631, ISSN 0024-9297

Orata, D. \& Buttry, A.D. (1987). Determination of ion populations and solvent content as functions of redox state and $\mathrm{pH}$ in polyaniline, Journal of American Chemical Society. Vol. 109, No. 12, (June 1987), pp. 3574-3581, ISSN 0002-7863

Robertis, E.D.; Neves, R.S. \& Motheo, A.J. (2008). Electropolymerization studies of PAni/(poly)luminol over platinum electrodes, Mol. Cryst. Liq. Crist. Vol. 484, pp. 322-334, ISSN 1542-1406

Royapa, A. T. ; Steadman, D. D. ; Tran, T.L. ; Nguyen, T. ; Prayaga, C.S. ; Cage, B. \& Dalal, N. (2001). Synthesis of sulfonated polyaniline by polymerization of the aniline heterodimer 4-aminodiphenilamine-2-sulfonic acid; Synthetic Metals, Vol. 123, No. 2, (September 2001), pp. 273-277, ISSN 0379-6779

Sanchís, C. ; Salavagione, H.J. ; Arias-Padilla, J. \& Morallón, E. (2007). Tuning the electroactivity of conductive polymer at physiological $\mathrm{pH}$. Electrochimica Acta, Vol. 52, No. 9, (February, 2007), pp. 2978-2986., ISSN 0013-4686

Shin-Jung, C. \& Su-Moon, P.; (2002). Electrochemistry of conductive polymers XXVI. Effects of electrolytes and growth methods on polyaniline morphology; Journal of Electrochemical Society; Vol. 149, No. 2, (February 2002), pp. E26-E34, ISSN 00134651

Varela, H. ; Torresi, R.M. \& Buttry, D.A. (2000). Mixed cation and anion transport during redox cycling of a self-doped polyaniline derivative in nonaqueous media. Journal of Electrochemical Society, Vol. 147, No. 11, (Novembre 2000), pp. 4217-4223, ISSN 0013-4651

Varela, H.; Torresi, R.M \& Buttry, D.A. (2000). Study of charge compensation during the redox process of self-doped polyaniline in aqueous media. Journal of Brazilien Chemical Society, Vol. 11, No. 1, (January-february), pp. 32-38, ISSN : 01035053

Varela, H. ; de Albuquerque Maranhão, S.L. ; Mello, R.Q.M ; Ticianelli, A.E. \& Torresi, R.M. (2001). Comparisons of charge compensation process in aqueous media of polyaniline and self-doped polyanilines ; Synthetic Metals ,Vol. 122 ; No. 2, (June, 2001), pp. 321-327, ISSN 0379-6779

Wei, X.L.; Wang, Y.Z.; Long, S.M.; Bobeczko, C. \& Epstein, A.J. (1996). Synthesis and Physical Properties of Highly Sulfonated Polyaniline, Journal of American Chemical Society, Vol. 118, No. 11, (December 1996), pp.2545-2555, ISSN 2156-8251

Yue, J.; Wang; Z.H.; Cromack, K.R.; Epstein, A.J.; MacDiarmid, A.G. (1991). Effect of sulfonic group on polyaniline backbone, Journal of American Chemical Society, Vol. 113, No. 7, (March 1996), pp.2665-X, ISSN 2156-8251

Zhang, G.F.; Chen, H.Y. (2000) Studies of polyluminol modified electrode and its application in electrochemiluminiescence analysis with flow system, Analytica Chimica Acta, Vol. 419, No. 1, (August 2000), pp. 25-31, ISSN 0003-2670 
Zhang, L.; Jiang, X.; Niu, L \& Dong, S., (2006). Syntheses of fully sulfonated polyaniline and its application to the direct electrochemistry of cytochrome C, Biosensors $\mathcal{E}$ Bioelectronics, Vol. 21, No. 7, pp. 1107-1115, ISSN 0956-5663 


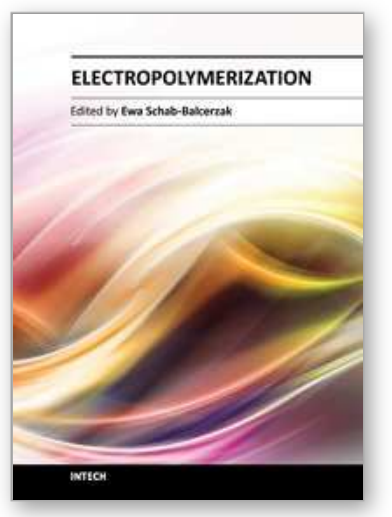

\author{
Electropolymerization \\ Edited by Dr. Ewa Schab-Balcerzak
}

ISBN 978-953-307-693-5

Hard cover, 214 pages

Publisher InTech

Published online 22, December, 2011

Published in print edition December, 2011

In recent years, great focus has been placed upon polymer thin films. These polymer thin films are important in many technological applications, ranging from coatings and adhesives to organic electronic devices, including sensors and detectors. Electrochemical polymerization is preferable, especially if the polymeric product is intended for use as polymer thin films, because electrogeneration allows fine control over the film thickness, an important parameter for fabrication of devices. Moreover, it was demonstrated that it is possible to modify the material properties by parameter control of the electrodeposition process. Electrochemistry is an excellent tool, not only for synthesis, but also for characterization and application of various types of materials. This book provides a timely overview of a current state of knowledge regarding the use of electropolymerization for new materials preparation, including conducting polymers and various possibilities of applications.

\title{
How to reference
}

In order to correctly reference this scholarly work, feel free to copy and paste the following:

Luz María Torres-Rodríguez, María Irene López-Cázares, Antonio Montes-Rojas, Olivia Berenice RamosGuzmán and Israel Luis Luna-Zavala (2011). Electrochemical Preparation and Properties of Novel Conducting Polymers Derived from 5-Amino-2naphtalensulfonic Acid, Luminol and from Mixtures of Them, Electropolymerization, Dr. Ewa Schab-Balcerzak (Ed.), ISBN: 978-953-307-693-5, InTech, Available from: http://www.intechopen.com/books/electropolymerization/electrochemical-preparation-and-properties-of-novelconducting-polymers-derived-from-5-amino-2naphta

\section{INTECH}

open science | open minds

\section{InTech Europe}

University Campus STeP Ri Slavka Krautzeka 83/A 51000 Rijeka, Croatia Phone: +385 (51) 770447 Fax: +385 (51) 686166 www.intechopen.com

\section{InTech China}

Unit 405, Office Block, Hotel Equatorial Shanghai No.65, Yan An Road (West), Shanghai, 200040, China 中国上海市延安西路65号上海国际贵都大饭店办公楼 405 单元 Phone: +86-21-62489820

Fax: $+86-21-62489821$ 
(C) 2011 The Author(s). Licensee IntechOpen. This is an open access article distributed under the terms of the Creative Commons Attribution 3.0 License, which permits unrestricted use, distribution, and reproduction in any medium, provided the original work is properly cited. 